\title{
IMPLEMENTASI TEOLOGIS TENTANG KESEMBUHAN KEDUA ORANG BUTA BERDASARKAN STUDI EKSEGESIS MATIUS 9:27-31
}

\author{
Arif Yupiter Gulo
}

Sekolah Tinggi Teologi Pokok Anggur Jakarta

glyupiarif@gmail.com

\begin{abstract}
Abstraksi
The article explain about the degeneration of Christian conviction to Jesus Christ in healing from disease them. Therefore the purpose of this research is to confirm that Jesus have authority to heal who believe in Him. This article of the qualitative research with exegetical-hermeneutic method, so calling to God, have faith in Him and only $\mathrm{He}$ is the true source of healing.
\end{abstract}

Artikel ini menjelaskan tentang kemorosotan keyakinan orang Kristen kepada Yesus Kristus dalam menyembuhkan penyakit mereka. Oleh karena itu, tujuan penelitian ini untuk menegaskan bahwa Yesus memiliki kuasa untuk menyembuhkan setiap orang yang percaya kepada-Nya. Artikel ini penelitian kualitatif dengan metode eksegesishermeneutik yang ditandai dengan seruan kepada Tuhan, beriman kepada-Nya dengan teguh dan hanya Dia sumber kesembuhan yang sejati.

\section{Kata Kunci: Kedua Orang Buta, Keyakinan, Kesembuhan.}

\section{PENDAHULUAN}

Albert Nolan mengatakan ada berjuta-juta orang yang sepanjang sejarah menyembah nama Yesus. Namun, tidak banyak yang memahaminya dan masih lebih sedikit lagi yang mencoba untuk mempraktekkan hal-hal yang ia inginkan supaya dilaksanakan. ${ }^{1}$ Terkait dengan itu, maka secara khusus penulis menemukan dalam pelayanan selama beberapa Tahun, di mana masih terdapat orang-orang Kristen yang

${ }^{1}$ Albert Nolan, OP, Yesus Bukan Orang Kristen, Yogyakarta: Kanisius, 2005, hal 17 
diragukan keyakinan dan imannya kepada Tuhan tatkala mereka menghadapi pergumulan dan masalah serta ketika mengalami penyakit maka mereka datang kepada Samaele'o dan dukun untuk meminta dalam memberikan solusi serta untuk menyembuhkan mereka. ${ }^{2}$ Berdasarkan dengan wawancara dengan salah seorang pendeta menegaskan bahwa praktik untuk datang kepada Samaele'o dan dukun berlangsung hingga sekarang terutama di pelosok-pelosok. Untuk itu, apa arti dukun dan samaeleo?

A dukun is a Malay term for shaman. Their societal role is that of a traditional healer, spirit medium, custom and tradition experts and on occasion sorcerers and masters of black magic. In common usage the dukun is often confused with another type of shaman, the pawang. It is often mistranslated into English as "with doctor" or "medicine man". Many self-styled dukun in Indonesia are simply scammers and criminals, preying on gullible and superstitious people who were raised to believe in the supernatural. ${ }^{3}$

Samaele'o (Paranormal) adalah Paranormal events are purportel phenomena described in popular culture, folk, and other non-scientific bodies of knowledge, whose existence within these contexts is described as beyond normal experience or scientific explanation. ${ }^{4}$ Oleh karena itu, mengapa masih ada yang percaya kepada Samaele'o dan dukun? Secara khusus di daerah pulau Nias dijelaskan dalam buku Tunaikan Tugas Pelayanan diungkapkan bahwa, sisa-sisa kepercayaan suku Nias yang masih menguasai hidup warga jemaat dan para pelayan, seperti: kepercayaan kepada arwah nenekmoyang, takyul dan ikatan-ikatan primodial serta pengaruh kuasa kegelapan (Okultisme). ${ }^{5}$ Padahal dalam Alkitab dengan keras melarang untuk tidak mengandalkan sesama umat manusia yang dinyatakan bahwa, Terkutuklah orang yang mengandalkan sesamanya manusia. tetapi diberkatilah orang yang berpengharapan kepada Tuhan. (Band. Yer. 17:1-9). Untuk itu, dalam tulisan ini akan menguraikannya tentang kesembuhan kedua orang buta berdasarkan Matius 9:27-31 dan implementasi teologis bagi kekristenan.

${ }^{2}$ Arif Yupiter Gulo, Tujuh Perkataan Yesus di Kayu Salib, Jawa Tengah: Lakeisha, 2020, hal 16

${ }^{3}$ http://en.m.wikipedia.org/wiki/dukun diakses 20 Juli 2020

${ }_{4}^{4}$ http://en.m.wikipedia.org/wiki/dukun diakses 20 Juli 2020

5 Fotarisman Zalukchu (Editor), Tunaikan Tugas Pelayanan, Medan: Cipta Pustaka, Media Perintis, hal 23 


\section{METODE PENELITIAN}

Metodologi yang akan dipakai untuk menyelenggarkan riset ini adalah pendekatan kualitatif dengan meteode "Hermeneutik-Eksegesis" dengan upaya untuk memahami makna teks ${ }^{6}$ dan analisa mendalam yang digabungkan dengan penguraian evaluative. Metodologi kualitatif adalah pendekatan analisa mendalam dengan penalaran induktif menggunakan teknik analisa untuk memahami suatu masalah secara subyektif. Tujuan dari metodologi kualitatif ini ialah untuk menemukan hipotesis menghasilkan teori baru. Teori baru ini adalah pengembangan dari teori yang ada (koresponden/koheren) yang merupakan konklusi (preposisi) yang berlaku umum. ${ }^{7}$ Tentu, Pengkajian dan penemuan teori baru seputar kebenaran terkait kesembuhan kedua orang buta berdasarkan Matius 9:27-31 dan implementasi teologis bagi kekristenan.

\section{STRUKTUR KOMPOSISI}

A Dua orang Buta Mengikuti-Nya (ay. 27)

B Kasihanilah Kami, hai anak Daud (ay. 27)

A Setelah Yesus Masuk ke Dalam Rumah (ay. 28)

B Percayakah kamu bahwa Aku dapat melakukan-Nya (ay. 28)

C Ya Tuhan, Kami Percaya (ay. 28)

B Yesus Menjamah (ay. 29)

C Meleklah mata mereka (ay. 30)

C Memasyurkan Dia ke seluruh daerah itu (ay. 31)

Ayat 27-31 menjelaskan tentang mukjizat yang dilakukan oleh Yesus kepada kedua orang yang buta. Dalam struktur A-B (ay. 27) menjelaskan tentang perjalanan Yesus berikutnya. Namun dalam perjalanan Yesus ini maka ada dua orang buta mengikut-Nya dengan berseru-seru memohon pertolongan untuk disembuhkan. Dalam ayat 28-30 bentuk strukturnya A-B-C-B-CC yang menjelaskan bahwa Yesus masuk dalam rumah, namun kedua orang buta itu terus mengikut Yesus yang gilirannya kedua orang buta tersebut mengalami kesembuhan yang ditandai bahwa mata kedua orang buta terbuka.

6 Andreas B. Subagyo, Pengantar Riset Kuantitatif dan Kualitatif, Bandung: Yayasan Kalam Hidup,2014, hal 125

${ }^{7}$ Dr. Yakob Tomatala dan Dr. Paskalinus Busthan, Penuntun Desain Riset bagi Program Tinggi Teologi, Jakarta: YT Leadership Foundation, 2010, hal 3 


\section{EKSEGESIS MATIUS 9:27-31}

\section{A. Dua Orang Buta: Kasihanilah Kami, Anak Daud}

Setelah Yesus menyembuhkan anak kepala rumah ibadat maka Ia meneruskan perjalanan-Nya. Namun dalam perjalanan-Nya maka ada dua orang buta mengikutiNya. Kata "buta" dalam bahasa Yunani $\tau v \phi \lambda o i$ artinya buta. ${ }^{8}$ Menurut Thomas mengatakan,

Blindness was a distressingly common disease in Palestine. It came partly from the glare of the eastern sun on unprotected eyes, and partly because people knew nothing of the importance of cleanliness and hygiene. In particular the swarms and clouds of unclean flies carried the infections which led to loss of sight. ${ }^{9}$

Namun, kedua orang buta tersebut tidak putus asa dan tidak tawar hati dengan berupaya untuk mengikuti Yesus dan berseru-seru mengatakan, "Kasihanilah Kami, hai

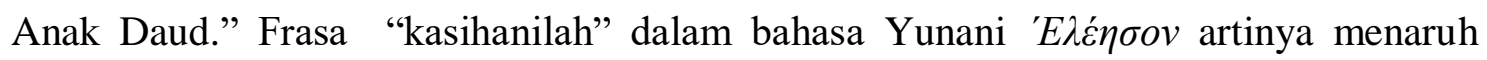
belas kasihan. ${ }^{10}$ Menurut Charles Haddon Spurgeon mengatakan bahwa, They were of one mind in reference to Jesus and therefore they went one way and use one prayer, to one and the same person. ${ }^{11}$ Dalam seruan kedua orang buta tersebut maka mereka menyebut Yesus sebagai Anak Daud. Menurut John Stott mengatakan bahwa, hal ini menunjukkan bahwa Yesus adalah "Anak raja” (sebuah gelar yang dia gunakan lebih sering daripada ketiga penulis kitab-kitab Injil lainnya sekaligus), yang berhak untuk mewarisi takhta Daud. ${ }^{12}$ Selain itu, Thomas mengatakan This is the first time in Matthew's Gospel that someone called Jesus the "Son of David" (cf. 1:1; 12:23; 15:22; 20:30, 31; 21:9, 15). This was a messianic title, and the blind men's use of it undoubtedly expressed their belief that Jesus was the Messiah. ${ }^{13}$ Lebih lanjut Charles Haddgon Spurgeon menambahkan bahwa, Even the blind could see that He was a King's Son. ${ }^{14}$ Bahkan diutarakan bahwa ungkapan Anak Daud ini, merupakan penggenapan nubuatan dari keturunan Daud (2 Samuel 7:14-16). Yesus adalah Mesias yang dijanjikan, yang berarti Dia harus dari garis keturunan Daud. Paulus menyatakan

\footnotetext{
${ }^{8}$ Hasan Susanto, Perjanjian Baru Interliner Yunani-Indonesia dan Konkordansi Perjanjian Baru (PBIK), Jilid II, Jakarta: Lembaga Alkitab Indonesia, 2014. hal 720

9 Thomas L. Constable, Notes on Mattew, ...hal 261

${ }^{10}$ Hasan Susanto, Perjanjian Baru Interlinear, Jilid II hal 252

${ }^{11}$ Charles Haddon Spurgeon, Commentary on Matthew: The Gospel of the King, hal 75

12 John Stott, Kristus yang Tiada Tara, Surabaya: Momentum, 2013, hal 10

${ }^{13}$ Thomas L. Constable, Notes on Mattew, hal 216

${ }^{14}$ Charles Haddon Spurgeon, Commentary. hal 75
} 
bahwa, "Tentang Anak-Nya, yang menurut daging diperanakkan dari keturuan Daud."

(Roma 1:3). Dalam artikel Sarapan Pagi Biblika mengungkapkan bahwa,

Matius 1:1 sebutan "Anak daud” diberikan kepada Yesus yang berarti Yesus adalah keturunan Daud. Matius menetapkan bahwa Yesus adalah keturunan Daud yang sah dengan menurut garis keturunan Yusuf yang berasal dari keturunan Daud. Walaupun Yesus dikandung oleh Roh Kudus, secara resmi (hukum Yahudi) Ia tetap dicatat sebagai anak Yusuf, secara hukum Yahudi - bukan secara darah - daging- Yusuf adalah ayah dari Yesus Kristus. Dan menurut hukum pula adalah anak Daud dalam pengertian "keturunan Daud" dari anaknya yang bernama Salomo. Sedangkan silsilah yang disajikan oleh Lukas merunut garis keturunan Yesus melalui kaum pria dalam garis keturunan Maria (yang juga dari keturunan Daud dari anaknya yang bernama Nathan). Lukas menekankan bahwa Yesus adalah anak kandung Maria. Dengan demikian para penulis kitab Injil menegaskan bahwa Yesus berhak menjadi Mesias baik secara hukum maupun secara biologis. ${ }^{15}$

Oleh karena itu, maka kedua orang buta itu, bukan hanya berseru untuk memohon pertolongan dan belas kasihan tetapi juga mereka memahami dan mengakui bahwa Yesus adalah anak Daud.

\section{B. Yesus Masuk ke dalam Rumah: Percayakah Kamu?}

Yesus masuk ke dalam rumah. Yunani oíkíav artinya rumah, tempat kediaman, keluarga, harta. ${ }^{16}$ Menurut Dr. Thomas mengatakan bahwa:

Probably Jesus did not heal these men outdoors for at least two reasons. He had already done two miracles outdoors, before many witnesses that day, and may have wanted to keep the crowd under control (cf. v. 30). Second, by bringing the blind men indoors, He heightened their faith, since it involved waiting longer for a cure. Jesus' question furthered this aim (v. 28). It also clarified that their cries for help came from confidence in Him, rather than just out of desperation, and it focused their faith on Jesus specifically, and not only God generally. ${ }^{17}$

Oleh karena itu, Yesus masuk ke dalam rumah bukan untuk menyembunyikan diri dari kerumunan orang banyak dan bukan juga untuk istirahat karena perjalanan jauh yang melelahkan-Nya tetapi Ia masuk ke dalam rumah dengan tujuan untuk menguji sejauhmana keyakinan serta kepercayaan kedua orang buta tersebut. Menurut Duncan Heaster menegaskan bahwa, The men had been cying (Gk. 'shrieking') to Him as He

15 Artikel Yesus Kristus, Tuan dan Anak Duad, http://www.sarapanpagi.org/yesus-kristus-tuandan-anak-daud-vt949.html diakses, 12 Agustus 2020

${ }^{16}$ Hasan Susanto, Perjanjian Baru Interlinear, Jilid II, hal 527

17 Thomas L Constable, Notes on Matthew, hal 262 
walking to the house; but he waited until He was in the house before healing them. ${ }^{18}$ Seruan kedua orang buta itu ditanggapi serius oleh Yesus mengatakan, "Percayakah kamu bahwa Aku dapat Melakukannya?" Kata percayalah dalam bahasa Yunani

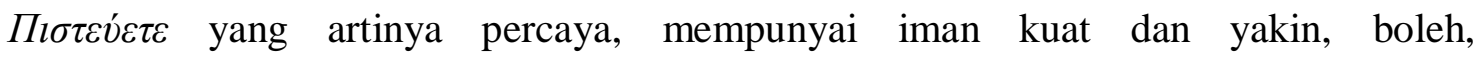
mempercayakan. ${ }^{19}$ Dalam buku Vine's mengatakan, to believe, also to be persuade of, signifies, in this sense of the word, reliance upon, not mere credence. ${ }^{20}$ Menurut Charles mengatakan, The Lord would have them express their faith and so he makes inquiry of them as to what they believe about Himself. Jesus makes no inquiry about their eyes, but only about their faith. ${ }^{21}$ Oleh karena itu, patut dikatakan bahwa Yesus masuk di dalam rumah untuk menguji dan mempertanyakan keyakinan dan iman kedua orang buta itu atas kuasa dan kemampuan Yesus dalam menyembuhkan mereka.

\section{Ya Tuhan,}

Setelah Yesus mempertanyakan keyakinan mereka atas kuasa-Nya dalam menyembuhkan maka kedua orang buta itu menjawab, "Ya Tuhan." Ungkapan Ya Tuhan dalam bahasa Yunani kó Perschbacher, (Ed) mengungkapkan,

Master (Matt. 12:8), et ai; an owner, possessor, Matt. 20:8, et al; a potentate, sovereign, Acts 25:26; a power, deity, 1 Cor. 8:5; the Lord Jesus Christ, Matt. 24:42; Mark 16:19; Luke 10:1; John 4:1; 1 Cor. 4:5, et al. freg; kúpıє, a term of respect of various force, Sir, Lord, Matt. 13:27; Acts 9:6. ${ }^{23}$

Dalam buku Vine's Complete Expository Dictionary of Old and New Testament dikatakan,

Properly an adjective, signifying "Having power" (Kuros) or "authority," is used as a noun, variously translated in the NT, "Lord," "master", "owner", "sir", a title of wide significance, occurring in each book of the NT save Titus and the Epistles of John. It is used (a) of an owner, as in Luke 19:33, cf. Matt. 20:8; Acts 16:16; Gal. 4:1; or of one who has the disposal of anything, as the Sabbath, Matt. 12:8; (b) of a master, ie., one to whom servis is due on any ground, Matt. 6:24; 24:50; Eph. 6:5; (c) of an Emperor or King, Acts 25:26; Rev. 17:14; (d) of idols,

\footnotetext{
${ }^{18}$ Duncan Heaster, Verse by Verse Commentary, hal 312

${ }^{19}$ Hasan Susanto, Perjanjian Baru Interlinear, Jilid II, hal 599

${ }^{20}$ Vine's Complete Expository Dictionary of Old and New Testamant, New York: Thomas Nelson Publisher, 1970, hal 61

${ }^{21}$ Charles Hadgon Supergeon, Commentary on Matthew: The Gospel of the King, hal 76

${ }^{22}$ Hasan Susanto, Perjanjian Baru Interlinear, Jilid II, hal 439

${ }^{23}$ Wesley J. Perschbacher, The Analitycal Greek Lexicon, USA: Hendrickson Publisher, 1990 hal 
ironically, 1 Cor. 8:5, cf. Isa. 26:13; (e) as a title of respect addressed to a father, Matt. 21:30, a husband, 1 Pet. 3:6, a master, Matt. 13:27; Luke 13:8, a ruler, Matt. 27:63, an angel, Acts 10:4; Rev. 7:14; (f) as a title of courtesy addressed to a stranger, John 12:21; 20:15; Acts 16:30; from the outset of His ministry this was a common form of addres to the Lord Jesus, alike by the people, Matt. 8:2; John 4:11, and by His disciples, Matt. 8: 2; Luke 5:8; John 6:68; (g) kurios is the Sept. and NT representative of the Heb. Jehovah (Lord in Eng. Version), see Matt. 22:24, and of Adonay, Lord, 1:22; it also occurs for Elohim, God, 1 Pet. 1:25. ${ }^{24}$

Oleh karena itu, tatkala kedua orang buta itu mengatakan bahwa Yesus sebagai Tuhan maka otomatis bahwa mereka mengakui bahwa Yesus sanggup dan mampu menyembuhkan mereka. Menurut Charles mengatakan, They could not see, but they could believe, and they did so. ${ }^{25}$ Dengan demikian, patut dikatakan bahwa kedua orang buta tersebut memiliki iman dan keyakinan yang teguh bahwa Yesus sanggup dan mampu untuk menyembuhkan mereka.

\section{Menjamah: Meleklah Mata Kedua Orang Buta}

Setelah mengakui dengan iman bahwa Yesus memiliki kuasa untuk menyembuhkan, maka Yesus menjamah mata mereka. Yunani $\ddot{\psi \alpha \alpha \tau o ~ a r t i n y a ~}$ menyalakan, menjamah, memegang, memeluk, menjamah (untuk menyampaikan berkat atau menyembuhkan, melukai. ${ }^{26}$ Menurut Thomas menuliskan bahwa,

Perhaps Jesus "touched" the "eyes" of the blind men, in order to help them associate Him with their healing, as well as because He was compassionate. However, it was primarily Jesus' word, not just His touch, that resulted in their healing (cf. Gen. 1). ${ }^{27}$

Selain itu, Actually touching the eyes, when the Lord had all manner of options open to Him, reflects His desire to connect with human weakness and need as directly and intimately as possible. ${ }^{28}$ Bahkan Charles Huddon Spurgeon menegaskan bahwa, He touched them with His hand, but they must also touch Him with their faith. ${ }^{29}$ Oleh karena itu Yesus menyentuh atau menjamah mata mereka karena mereka memiliki keyakinan bahwa Yesus dapat menyembuhkan mereka. Itu sebabnya Yesus

\footnotetext{
${ }^{24}$ Vine's Complete Expository Dictionary of Old and New Testament Word, hal 379

${ }^{25}$ Charles Haddon Supergeon, hal 76

${ }^{26}$ Hasan Susanto, Perjanjian Baru Interlinear,... Jilid II, hal 103

27 Thomas L. Constable. hal 262

${ }^{28}$ Duncan Heaster, Verse by Verse Commentary. hal 313

${ }^{29}$ Charles Huddon Spurgeon, hal 76
} 
menegaskan bahwa, "Jadilah kepadamu menurut imanmu" (ay. 29). Menurut Duncan mengatakan,

This might imply that the extent of their restored vision was dependent upon the degree of their faith. In some cases, the Father and Son operate in a sovereign way, as with the blind man of John 9 who was cured without knowing who Jesus was. In others, their action and the extent of it is directly in proportion to human faith. $^{30}$

Hal ini menunjukkan bahwa iman mereka kepada Yesus yang merupakan tolak ukur yang absolute untuk dapat menyembuhkan mereka sehingga pada gilirannya ditekankan bahwa kedua orang buta tersebut menjadi "Meleklah" mata mereka. Frasa "Meleklah" dalam bahasa Yunani $\eta v \varepsilon \dot{\omega} \chi \theta \eta \sigma \alpha v$ artinya membuka, terbuka. ${ }^{31}$ Selain itu, They both saw. The double miracle was wrought at the same moment. ${ }^{32}$ Dengan demikian maka kedua rang buta tersebut mata mereka terbuka. Namun, ketika mereka sembuh Yesus berpesan dengan tegas kepada mereka supaya jangan seorang pun mengetahui hal ini tetapi mereka keluar dan memasyurkan Dia ke seluruh daerah itu. Mereka memasyurkan Dia menunjukkan sukacita yang mereka rasakan. Frasa

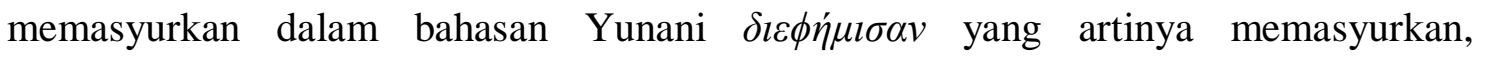
menyebarkan ke mana-mana. ${ }^{33}$ Kendati mereka berdua sudah dilarang untuk menyebarkannya. Namun sukacita mereka tidak terbantahkan karena mereka dapat melihat karena mata adalah pelita tubuh untuk dapat berkaktifitas seperti dengan orang lain. (Band. Matius 6:22).

\section{HASIL}

Berdasarkan dengan eksegetis di atas maka kedua orang buta tersebut mengalami kesembuhan bukan karena ritual keagamaan, bukan karena intervensi dari kuasa kegelapan tetapi murni oleh karena iman kepada Tuhan yang ditandai seperti uraian berikut:

\footnotetext{
${ }^{30}$ Duncan Heaster, Verse by Verse Commentary, hal 314

${ }^{31}$ Hasan Susanto, Perjanjian Baru, Jilid II, hal 77

${ }^{32}$ Charles Haddon Spurgeon, hal 76

${ }^{33}$ Hasan Susanto, Perjanjian Baru Interlinear, Jilid II, hal 190
} 


\section{a. Berseru dengan Iman}

Berseru dalam Kamus Besar Bahasa Indonesia mengungkapkan bahwa memanggil atau menarik perhatian dengan suara nyaring. ${ }^{34}$ Namun, bagaimana berseru yang sesungguhnya dalam perspektif Alkitab? Hal ini mengacu dalam Ibrani 11: 1 dinyatakan bahwa, "iman adalah dasar dari segala sesuatu yang kita harapkan dan bukti dari segala sesuatu yang tidak kita lihat." Hal ini menunjukkan bahwa iman merupakan

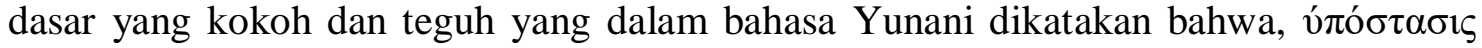
hakikat, keyakinan, kenyataan. ${ }^{35}$ Oleh karena itu, dalam Matius 17:20 dinyatakan bahwa, "Ia berkata kepada mereka: "Karena kamu kurang percaya. Sebab Aku berkata kepadamu: Sesungguhnya sekiranya kamu mempunyai iman sebesar sebiji sesawi saja kamu dapat berkata kepada gunung ini: pindah dari tempat ini ke sana, -maka gunung ini akan pindah, dan takkan ada yang mustahil bagimu." Menurut Dieter Backer mengatakan bahwa,

Dalam Perjanjian Baru iman memainkan peranan yang sentral. Iman pada dasarnya diartikan sebagai kepercayaan dan pengharapan, tetapi iman dapat juga berarti bahwa sesuatu hal dianggap benar dan bahwa pengenalan tentangnya mengikat pemikiran. Dalam Injil-Injil Sinopsis, iman pada pokoknya diartikan sebagai suatu kepercayaan. Dalam Injil Yohanes iman berarti kepercayaan, tetapi tampak juga bahwa salah satu ciri khas iman itu adalah pengenalan. Paulus menerangkan tentang iman dalam arti kepercayaan pribadi kepada Kristus (Gal. 2:16; Rm 3:22) dan kepada Allah (2 Kor. 1:9). ${ }^{36}$

Dengan demikian bahwa iman menjadi dasar yang absolute dalam menyembuhkan setiap penyakit yang dirasakan. Oleh karena itu, tatkala Yesus menyembuhkan maka selalu ditekankan bahwa, "pergilah imanmu telah menyelamatkan engkau" (Band. Lukas 17:19).

\section{KESIMPULAN}

Berdasarkan uraian di atas maka dapat dikatakan bahwa kesembuhan kedua orang buta tersebut bukan karena kekuatan mereka dan bukan karena pertolongan dari kuasa lain tetapi berdasarkan dengan keyakinan dan kepercayaan mereka kepada Yesus. Oleh karena itu, patut dikatakan bahwa keyakinan dan iman yang tidak diragukan dan yang berakar kepada-Nya dengan sangat dalam. Dalam hal ini Paulus menegaskan bahwa,

\footnotetext{
${ }^{34}$ Kamus Besar Bahasa Indonesia, online, diakses, 15 Agustus 2020

${ }^{35}$ Hasan Susanto, Perjanjian Baru Interlinear... Jilid II, hal 734

${ }^{36}$ Dr. Theol. Dieter Becker, Pedoman Dogmatika, Jakarta: Gunung Mulia, 2001, hal 19
} 
"Hendaklah kamu berakar di dalam Dia dan dibangun di atas Dia, hendaklah kamu bertambah teguh dalam iman yang telah diajarkan kepadamu, dan hendaklah hatimu melimpah dengan syukur." (Kol. 2:7). Untuk itu, upaya yang ditempuh supaya berakar dalam iman kepada-Nya. Maka dalam hal ini Paulus mengatakan bahwa, "jadi, iman timbul dari pendengaran, dan pendengaran oleh firman Kristus.” (Roma 10:17). Oleh karena itu maka ditegaskan bahwa, "Setiap orang yang mendengar perkataan-Ku ini dan melakukannya, ia sama dengan orang bijaksana, yang mendirikan rumahnya di atas batu." (Mat. 7:24). 


\section{DAFTAR PUSTAKA}

Becker, Dr. Theol. Dieter, Pedoman Dogmatika, Jakarta: BPK Gunung Mulia, 2001

Constable, Thomas L. Notes on Mattew, ...

Dickson, David. A Brief Exposition of the Evangel of Jesus Christ According to Matthew, England: Quinta Press. 2009

Nolan, Albert Nolan, OP. Yesus Bukan Orang Kristen, (Yogyakarta: Kanisius, 2005) hal 17

Zalukhu, Fotarisman (Editor). Tunaikan Tugas Pelayanan, Medan: Cipta Pustaka, Media Perintis, 2010

Heaster, Duncan. Verse by Verse Commentary on Gospel of Matthew, christadelphian matthew gospel commentary verse chapter, 2014

Susanto, Hasan. Perjanjian Baru Interliner Yunani-Indonesia dan Konkordansi Perjanjian Baru (PBIK) jilid I dan II, Jakarta: Lembaga Alkitab Indonesia, 2014

Subagyo, Andreas B. Pengantar Riset Kuantitatif dan Kualitatif, Bandung: Yayasan Kalam Hidup,2014

Stott, John ,Kristus yang Tiada Tara, Surabaya: Momentum, 2013

Perschbacher, Wesley J. The Analitycal Greek Lexicon, USA: Hendrickson Publisher, 1990

Tomatala, Dr. Yakob dan Busthan, Dr. Paskalinus, Penuntun Desain Riset bagi Program Tinggi Teologi, Jakarta: YT Leadership Foundation, 2010

Spurgeon, Charles Haddon, Commentary on Matthew: The Gospel of the King,....

Yupiter Gulo, Arif, Tujuh Perkataan Yesus di Kayu Salib, Jawa Tengah: Lakeisha, 2020

\section{KAMUS-KAMUS}

Kamus Besar Bahasa Indonesia Online

Vine's Complete Expository Dictionary of Old and New Testament, New York: Thomas Nelson Publisher, 1985 


\section{WEBSITE}

http://en.m.wikipedia.org/wiki/dukun diakses 20 Juli 2020

Artikel Yesus Kristus, Tuan dan Anak Duad, http://www.sarapanpagi.org/yesus-kristus-tuan-dananak-daud-vt949.html diakses, 12 Agustus 2020

\section{WAWANCARA}

Wawancara via handpone dengan Pdt. Temasokhi Zebua, S.Th (Pendeta GNKPI), 12 Agustus 2020 